\title{
Profound limb deficiency, thoracic dystrophy, unusual facies, and normal intelligence: a new syndrome
}

\author{
SADIKA A AL-AWADI, AHMAD S TEEBI, TALAAT IFARAG, \\ KAMAL M NAGUIB, AND MOHAMMED YEL-KHALIFA \\ From the Kuwait Medical Genetics Centre, Safat, Kuwait.
}

SUMMARY A newly recognised profound limb deficiency malformation syndrome in two Arab $\overrightarrow{\dot{\omega}}$ sibs of different sexes with consanguineous parents is described. Additional features, which include thoracic dystrophy, unusual facies, and normal intelligence, are consistent in both of $\frac{\circ}{7}$ them. Autosomal recessive inheritance is suggested.

\begin{abstract}
Absent limb defects are variable malformations with marked clinicogenetic heterogeneity. The defect may be an isolated structural anomaly or part of a malformation syndrome. It may be transverse or longitudinal, affecting different parts of a limb or more than one limb. ${ }^{1}$ The defect may occur sporadically with no genetic cause or may be genetically determined with different modes of inheritance. ${ }^{2}$
\end{abstract}

\section{Case reports}

The two sibs were born to phenotypically normal first cousin parents. They had three younger phenotypically normal children, with no family history of a

Received for publication 3 January 1984

Accepted for publication 7 April 1984.

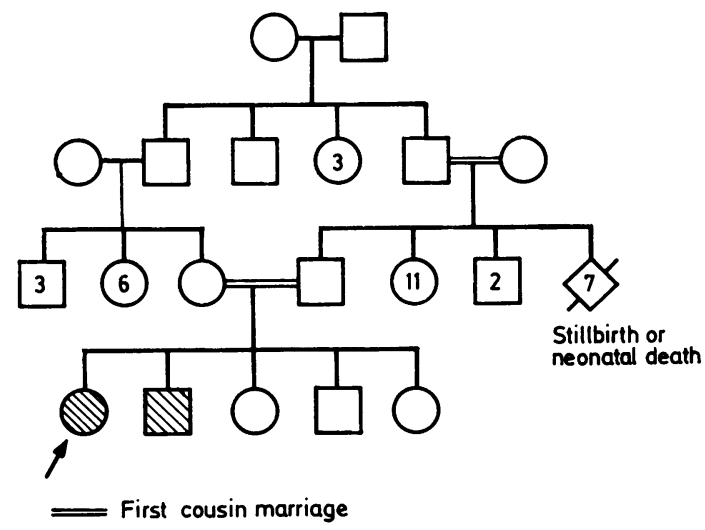

FIG 1 Family pedigree. Numbers in boxes and circles indicate number of children. similar condition (fig 1). The parents came from a small village on the west bank of the river Jordan $\vec{\oplus}$ (Silat Al-Hartheya). The pregnancy and delivery of were uncomplicated in both the sibs and they had average birth weight. Limb deficiency defects were noted at birth. They were brought to our attention for evaluation and management, when case 1 was 10 years old and case 2 was 8 years old.

CASE 1

Case 1 is a 12 year old shy girl, born on 7.11 .71 (fig

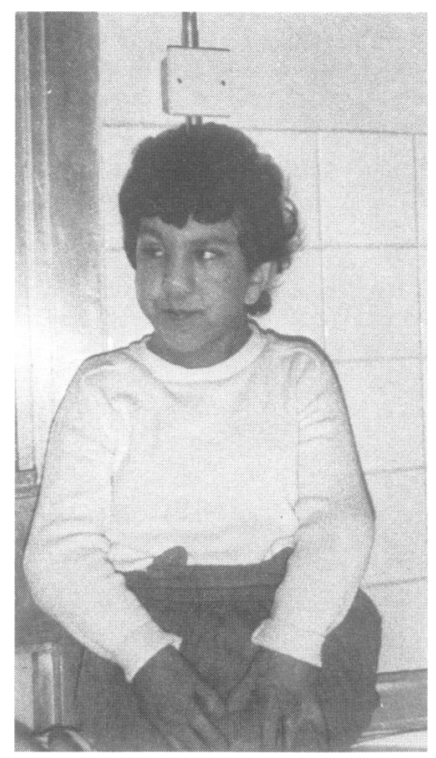

FIG 2a Case 1. 


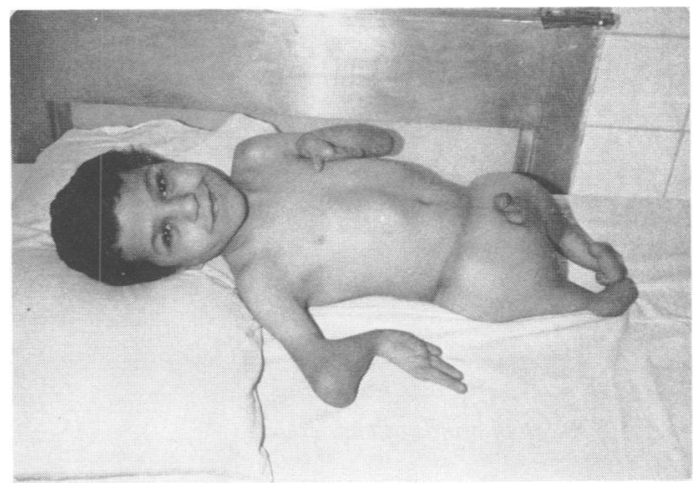

FIG 2b Case 2.

2a), with an elongated face, a right epicanthic fold, broad nasal bridge and nose, broad neck, and a barrel shaped chest with prominent sternum. Her shoulders and arms look normal with normal humeri but with no elbow joint and a contraction deformity at the site. Her forearms are slightly shortened with relatively short radii and absent ulnae (fig 3 ). Her hands each have four digits with vestigial nails in some of them. The fifth ulnar ray is missing with fusion of some of the carpal bones (fig 3 ). The hands have a poor grip but she can feed herself. There is gross pelvic malformation with very short appendages consisting of one lower limb bone with a detached head and neck of the femur. The ankle joints are primitive and there is only one unidentifiable tarsal bone. The feet are malformed with only two rays each (fig 4). Her lower limbs are useless. Her IQ was assessed and found to be 100 (Griffiths mental development scale).

\section{CASE 2}

Case 2 is an intelligent 10 year old boy, born on 16.6.73, who can get about on his bottom and seems happy. He showed a similar phenotype to case 1 (fig $2 b$ ) with severe contraction deformities at the site of the elbow joints. There are three digits on the right side (fig 5) with vestigial nails in two of them and two digits on the left with a vestigial nail in one (fig 5).

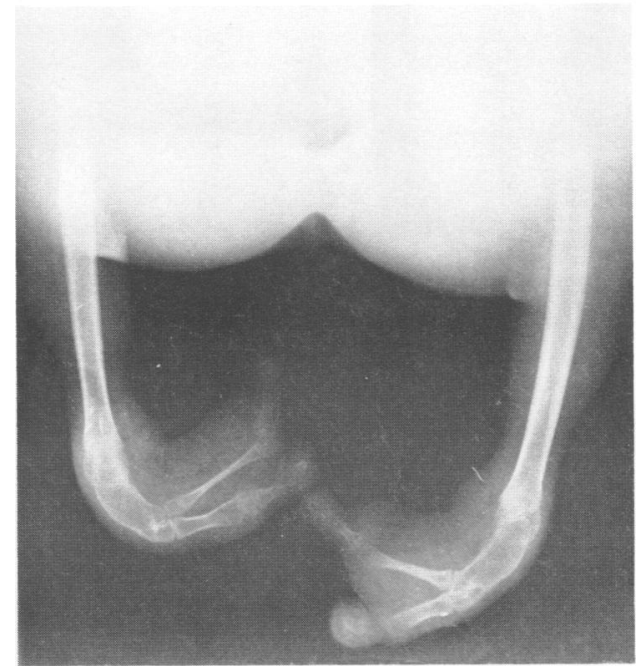

FIG $4 X$-ray of legs of case 1.

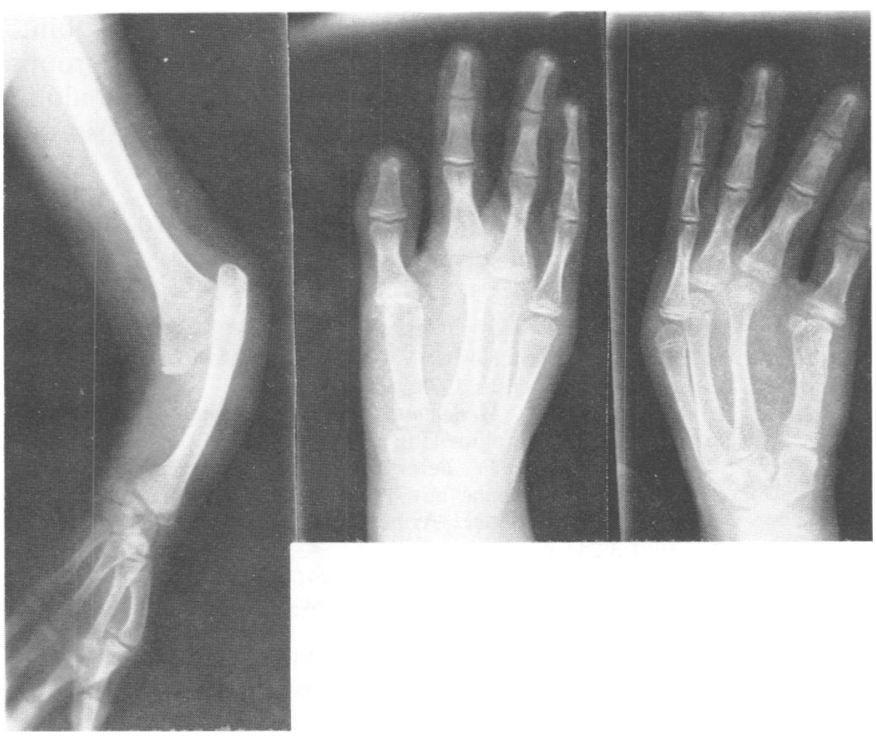

FIG $3 X$-rays of arm and hands of case 1. 


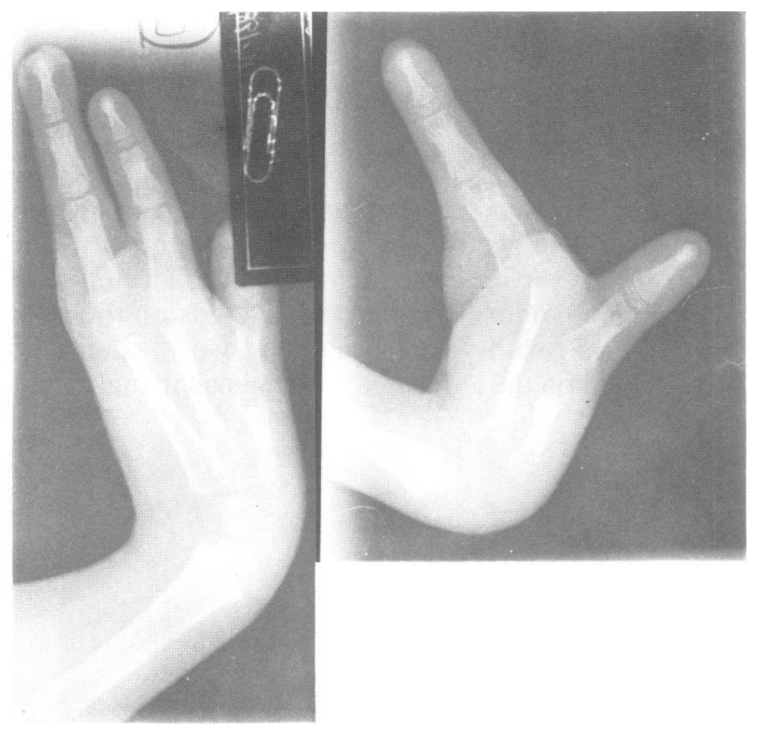

FIG $5 X$-ray of hands of case 2.

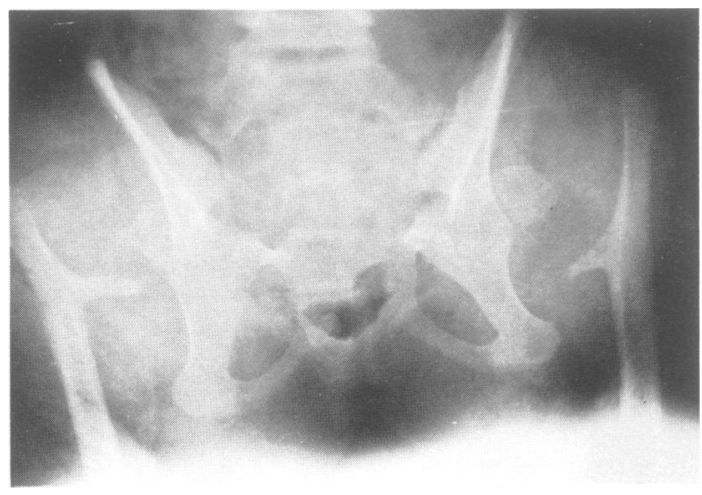

FIG $6 X$-ray of pelvis of case 2.

His pelvis is grossly disordered (fig 6) with anteverted external genitalia, inguinal testes, a deep anal pit, and no gluteal cleft. The lower appendages are also severely disordered and useless, with one leg bone, hypoplastic ankle joints, one tarsal bone, and two hypoplastic deformed toes on the right and one hypoplastic toe on the left.

\section{Discussion}

It seems that these two sibs have a new syndrome which has not been previously described. ${ }^{2}$ The similarity in the abnormalities in the two sibs, which include a profound deficiency of the upper and lower extremities with only slight variability in the expression, thoracic dystrophy, unusual facies, and normal intelligence, points, in the absence of teratogenic factors, to a genetic aetiology. This is probably an autosomal recessive gene carried by the consanguineous parents, originating from a common founder ancestor in the small semi-isolated population. Both sibs have hypoplastic femora and absent ulnae and fibulae, but they differ from the cases reported by Kuhne et al. ${ }^{3}$ The synonym for femur fibula ulna syndrome in the United States is proximal femoral focal deficiency (PFFD), a term used by Aitken ${ }^{4}$ to define a group of malformations characterised by partial deficiencies of the proximal portion of the femur involving the iliofemoral joint. He classified PFFD into four radiological subgroups depending on the development of the acetabulum, femoral head, and femoral shaft. However, in our opinion, these cases are dissimilar.

We thank Dr Ruth Wynne Davies, Oxford, for help with this manuscript.

\section{References}

1 Temtamy S, McKusick VA. The genetics of hand malformations. Birth Defects 1978;3:155-6.

${ }^{2}$ McKusick VA. Mendelian inheritance in man. 6th ed. Baltimore: Johns Hopkins University Press, 1983.

${ }^{3}$ Kuhne D, Lenz W, Petersen D, Schonenberg H. Defekt von Femur und Fibula mit Amelie, Peromelie Oder Ulnaren Strahldefekten der Arme: Ein Syndrom. Humangenetik 1967;3:244-63.

4 Aitken GT. Proximal femoral focal deficiency; a congenital anomaly. Washington: National Academy of Science, 1969.

Correspondence and requests for reprints to $\mathrm{Dr}$ Sadika A Al-Awadi, Kuwait Medical Genetics Centre, PO Box 4080, Safat, Kuwait. 